\title{
Embryoprotein TWIST distribution in breast cancer cells MDA-MB-231 treated with 5-Fluorouracil and malnutrition
}

\author{
Jesica Escobar-Cabrera, Angelina Rodríguez-Torres, Laura Berumen-Segura, \\ Guadalupe García Alcocer*
}

Facultad de Química, Universidad Autónoma de Querétaro, Centro Universitario, Querétaro, México. Email: leguga@email.com

Received 16 August 2011; revised 19 October 2011; accepted 9 November 2011.

\begin{abstract}
TWIST is a transcription factor that belongs to the family of helix-loop-helix proteins involved in metastasis with essential role regulating cell movement during early development, as well as in the tumor progression and metastasis of many cancers including breast cancer. It will be interesting to study the relation among cancer chemotherapy, malnutrition and the transcription factors like TWIST in order to explore the risk to metastasis. We used breast cancer line MDA-MB-231. Cell cultures were treated with 5-Fluorouracil (5-Fu), as well as changes in serum and nonessentials amino acid (NEAA), to explore the cell viability and the cellular distribution of TWIST by immunocytochemistry. Our results indicate that cell viability decreased significantly with 5 -Fu treatment whereas no changes were observed in malnutrition treatment. On the other hand, TWIST protein significantly increased its distribution in cytoplasm of treated groups with malnutrition as well as in those treated with 5-Fu compared with the control. These results suggest that TWIST translocation was modified by the treatments and further studies are necessary to suggest that TWIST could be a tag protein to avoid metastasis.
\end{abstract}

Keywords: TWIST; Breast Cancer; 5-Fu; 5-Fluorouracil; NEAA; Nonessential Amino Acid

\section{INTRODUCTION}

TWIST protein is a highly conserved transcription factor, initially identified in Drosophila, with an essential role in regulating cell movement during early development. It belongs to the family of basic helix-loop-helix (bHLH) proteins that can homodimerize or heterodimirize with other proteins of the same family like E proteins, MASH1, MASH2, SCL etc. [1-4]. TWIST has two homologues in vertebrates that are expressed in a broad range of embryonic and adult tissues: TWIST 1 and TWIST 2 [5]. The activation of the two TWIST gene could be associated with interleukin-6, which promotes STAT3 activation and their bound to the human TWIST promoter starting their transcriptional activity [6]. Besides the important role during ontogeny, TWIST has been reported over expressed in distinct types of cancer, including breast cancer and metastasis [7].

Carcinogenesis involves initiation, progression and metastasis [8]. It is important to study the different events involved in the cancer progress as TWIST over expression, which has been related with the same biological activity during normal development in tumor progression as cell migration $[9,10]$. The metastasis of breast cancer remains essentially incurable [11]. One of the drugs used in breast cancer is 5-Fluorouracil (5-Fu) which interferes with thymidylate synthase [12]. It has been reported by epidemiological studies the relation between cancer and diet [13], as well as the relation of chemotherapy treatment with metastasis remain unclear. In this work, we study the viability and the cellular distribution of TWIST in cancer breast line cells MDAMB-231, treated with malnutrition and 5-Fu.

\section{MATERIALS AND METHODS}

\subsection{Antibodies and Reagents}

Antibodie against TWIST were purchased from Santa Cruz Biotechnology, USA. Polyclonal anti-rabbit-HRP were obtained from Invitrogen. 5-Fluorouracil drug was obtained from Columbia Laboratories, Mx (50 $\mu \mathrm{g} / \mu \mathrm{l})$, DAB (Sigma, Germany) Culture medium (DMEM), amino acid glutamine, nonessentials amino acids and antibiotics were obtained from Gibco (Zurich Switzerland).

\subsection{Cell line}

The breast cancer cell line used was MDA-MB-231. The 
cells were cultured in Dulbecco's modified Eagle's medium (DMEM) with 10\% and 2\% fetal bovine serum (FBS), 1\% L-glutamine, 1\% nonessential amino acids (NEAA) $1 \%$ antibiotics mix (penicillin-streptomycin). The cultures were maintained in a humidified incubator at $37^{\circ} \mathrm{C}$ with $5 \% \mathrm{CO}_{2}$. To measure viability, cell were seeded at $3 \times 10^{4}$ per well in 12-well dish for 48 hours, for each treatment. The cells from three dishes were trypsinized and stained with trypan blue. Each experiment was reproduced 3 times.

\subsection{Immunocytochemical Analysis}

The cells were washed three times with PBS (phosphate buffer saline, $\mathrm{pH}: 7.4$ ) and then peroxidase activity was blocked for 30 minutes in a PBS solution, containing 1\% hydrogen peroxide for 1 hour. The cells were washed and blocked with milk 3\% (BIO-RAD) in PBT for two hours. For specific immunoreactivity detection, the cells were washed three times with PBS and incubated with the rabbit polyclonal anti-TWIST antibody in PBT (phosphate buffer saline with triton $0.5 \% \mathrm{X}-100,1: 200$ ) at $4^{\circ} \mathrm{C}$ overnight. The next day the cells were washed three times with PBS, and then incubated with the secondary anti rabbit- HRP antibody (1:300) in PBT and finally the stain was developed with DAB. Negative control was stained by omitting the primary antibody. We analyzed 3 different experiments with 250 cells each.

\subsection{Statistical Analysis}

The cell viability was calculated as the percentage over control. Differences in mean values were evaluated using either one-way ANOVA with Tukey test to determine differences among treatments groups. $P<0.05$ was regarded as statistically significant. All data are given mean \pm standard error.

\section{RESULTS}

To understand the role of FBS on proliferation and viability of MDA-MB-231 cells, we cultured cells with $10 \%, 2 \%$ FBS and $0.5 \%$ albumin for 48 hours. The cell viability with $2 \%$ FBS was $82.66 \% \pm 10.74 \%$ ee and $16.5 \% \pm 5.32 \%$ ee with albumin, both in relation to the control group (10\% of FBS). The albumin treatment showed statistical difference compared to control. The $2 \%$ of FBS concentration was elected to the following experiments (Figure 1).

To evaluated the effect of nonessential amino acids we cultured cells with $1 \%, 0.5 \%$ and without NEAA. The viability obtained did not have statistical differences compared to the control with NEAA 1\% (Data not shown). The condition with NEAA depletion was used in the following experiments on viability with 5 -Fu added and the cellular distribution of TWIST.

To know the 5-Fu effect on cell viability, the cultures were subjected to different drug concentrations or without 5-Fu (control group), the cells growth allowed 33.1\% $\pm 13.8 \%$ ee in $5 \mu \mathrm{M}$ concentration; $39.01 \% \pm 8.75 \%$ ee in $50 \mu \mathrm{M}, 34.54 \% \pm 6.08 \%$ ee in $100 \mu \mathrm{M}$ and $19.6 \% \pm$ $9.58 \%$ ee in $200 \mu \mathrm{M}$. All concentrations showed significant difference compared with the control but not among the treatments (Figure 2).

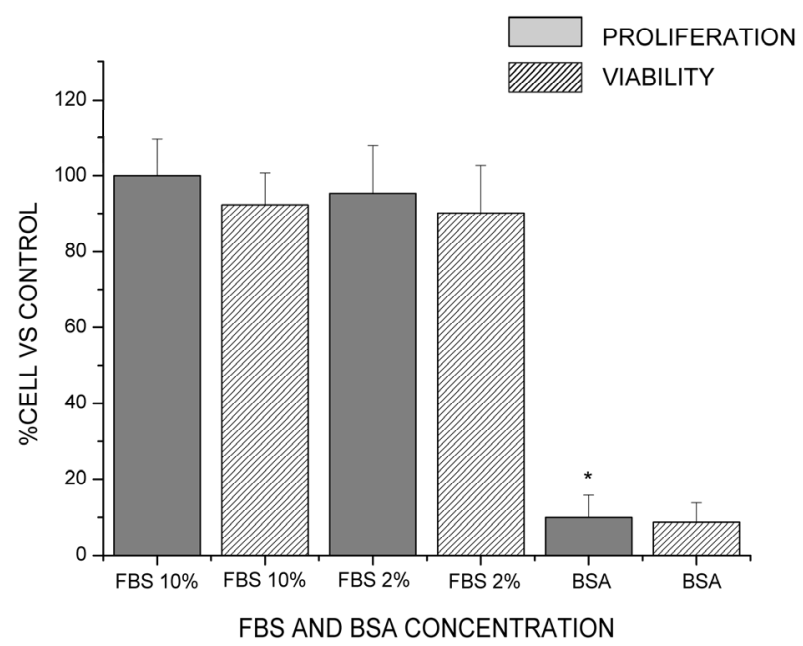

Figure 1. Proliferation and viability in malnutrition cells. The MDA-MB-231 viability cells significantly decreases in albumin treatment $(\mathrm{P}<0.05)$. The results are the mean values of three independent experiments \pm standard error.

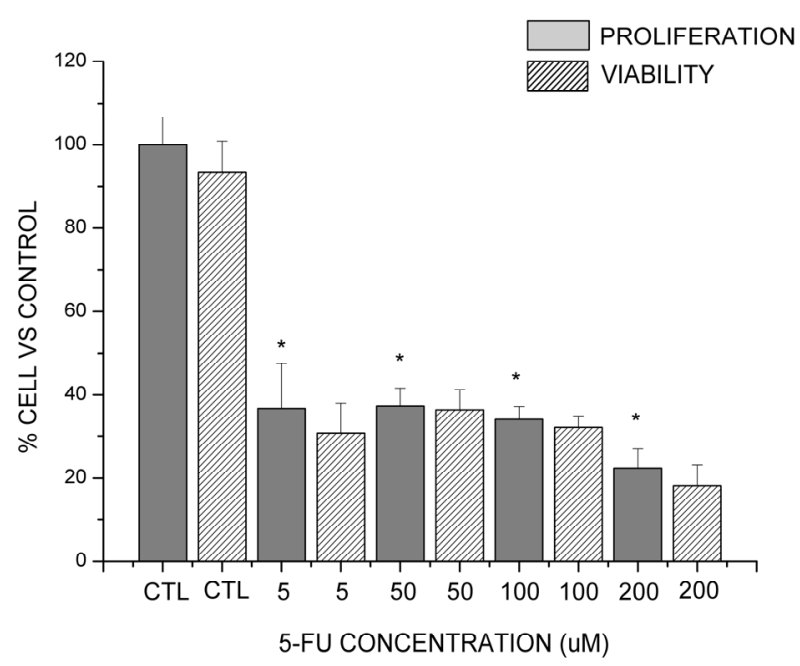

Figure 2. 5-Fluorouracil effects in MDA-MB-231 cells. All 5-Fu different concentrations caused significant proliferation and viability decrease compared with the control (with no drug) and non statistical differences were observed among treatments $(P<0.05)$. The groups were cultured with $2 \%$ FBS and optimal nonessential amino acids concentration (1\%). The results are given as mean values of 3 independent experiments \pm standard error. 
In the control group the staining was observed in $96.3 \% \pm 1.3 \%$ ee of total cells analyzed (250), the depletion of nonessential amino acids showed staining cells in $88.6 \% \pm 5.3 \%$ ee, the 5 -Fu $(50 \mathrm{uM})$ in the $80.6 \% \pm$ $13.3 \%$ ee, the combination of depletion of NEAA and 5 -Fu in $87 \% \pm 3.8 \%$ ee. The immunocytochemical results indicated different TWIST staining zones: nucleus, cytoplasm and both (nucleus-cytoplasm) (Figure 3). The treatments did not cause significant difference immunostain decrease compared to the control in the total cells. On the other hand, in the specific zone the depletion of NEAA, the 5-Fu and both factors added together showed a significant decrease in nucleus-cytoplasm stain compared to the control (Figure 4).

\section{DISCUSSION}

The high viability in $10 \%$ and $2 \%$ of FBS cultures compared to those cultures with $0.5 \%$ BSA-medium with lower viability were consistent with the viability in osteoblasts experiments, as well as in stem cells added with different FBS concentrations [14,15]. On the other hand, our results were different from those experiments in Chinese hamster ovary cells because they reported a decrease in the viability with FBS [16]. They also differed from the experiments in human mesenchymal steam cells that reported an increased viability with the FBS reduction and observed a higher level of viability when used 1\% human serum albumin instead of FBS [17]. One possibility in the viability differences with the FBS could be associated with the distinct cell lines requirements and their specific growth nutrients sensibilities [18]. In human cells, the growth factors also participate in the capacity to synthesize the necessary proteins for their survivor and proliferation, even in conditions of nutrients deprivation [19].

Our results indicate that the viability was not affected by nonessentials amino acids as has been reported before with mice feds deficient tryptophan tumoral cells [2022]. On the other hand, a decrease in the viability has been reported in rat brain postmitotic neurons depleted in tryptophan, isoleucin, metionin and cholin [23]. The differences could be associated with the use of essentials amino acids instead nonessentials. The essentials amino acids like leucine, isoleucine and valine increase the protein synthethize, and decreases proteolisis. They are also important for cell survival [24]. Another possibility could be associated to the serum grow factors activity, that can improve the cell development inducing the use of peptides, like source of amino acids in nutrients deprivation conditions [19].

The viability cells decrease by the citotoxic effects of Fluorouracil was consistent with those reported in linfoblastic cell cancer, thyroid cell cancer, and mouse
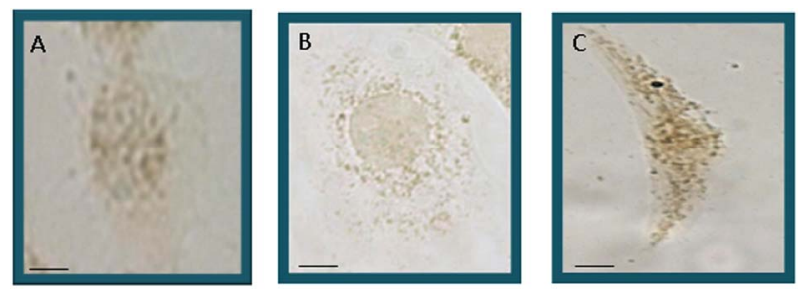

Figure 3. TWIST cell distribution in MDA-MB-231 cells. Representative cells of TWIST protein immunocytochemistal staining, (A) Stained cell in nucleus; (B) Stained cell in cytoplasmic zone; (C) Stain of TWIST in nucleus and cytoplasm. 40X magnifications. Bar $10 \mu \mathrm{m}$.

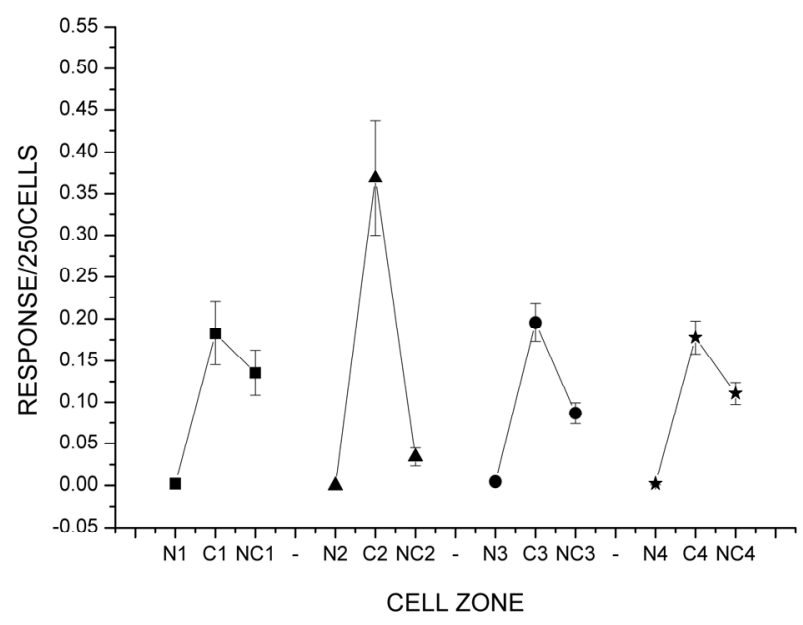

Figure 4. TWIST distribution in treated cells with 5-Fu and malnutrition. Control cells with optimal nonessentials amino acids concentrations (1) showed no statistical difference among cytoplasm (C) and nucleus-cytoplasm (NC) zones. The staining was higher in cytoplasm than nucleus-cytoplasm in all treated groups, compared to the control. The lines indicated a mean \pm ee. The treatments were: control with $1 \%$ NEAA (1), without NEAA (2), 1\% NEAA and 5-Fu (3) without NEAA and 5-Fu (4).

tumor cell [25-27]. The 5-Fu damage may be associated with a fail on repair system [26], and could be possible that higher doses induce total cell death. The Fluorouracil toxicity mechanism could be associated with the sintetase timidilate inhibition vía Fas [28].

The depletion on NEAA, the treatment with 5-Fu and both factors added together were not enough to eliminate TWIST immunosignal from cells MDA-MB-231. It was interesting to observe a cytoplasm immunosignal increase in all treated groups; those results may be related to changes in protein conformation or mutations in the TWIST gen induced by the treatment [29]. The increase of TWIST presence in cytoplasm affected its function as transcription factor.

\section{ACKNOWLEDGMENTS}

The authors thank to Dr. Teresa García Gasca and Dr. Aracely Anaya 
for their valuable suggestions.

\section{REFERENCES}

[1] Yang, J., Mani, S., Donaher, J., Ramaswamy, S., Itzykson, R., Come, C., Savagner, P., Gitelman, I., Richardson, A. and Weinberg, R.A. (2004) Twist, a master regulator of morphogenesis, plays an essential role in tumor metastasis. Cell, 117, 927-939. doi:10.1016/j.cell.2004.06.006

[2] Puisieux, A., Valsesia-Wittmann, S. and Ansieau, S. (2006) A twist for survival and cancer progression. British Journal of Cancer, 94, 13-17. doi:10.1038/sj.bjc.6602876

[3] Vesuna, F., Diest, P., Chen, J.H. and Raman, V. (2008) Twist is a transcriptional repressor of E-cadherin gene expression in breast cancer. Biochemical and Biophysical Research Communications, 367, 235-241. doi:10.1016/j.bbrc.2007.11.151

[4] Hamamori, Y., Wu, H.Y., Sartorelli, V. and Kedes, L. (1997) The basic domain of myogenic basic helix-loophelix (bHLH) Proteins Is the Novel Target for Direct Inhibition by Another bHLH protein, twist. Molecular and Cellular Biology, 17, 6563-6573.

[5] Sosic, D. and Olson, E.N. (2003) A new twist on twist: Modulation of the NF-KappaB pathway. Cell Cycle, 2, 76-78. doi:10.4161/cc.2.2.338

[6] Cheng, G.Z., Zhang, W.Z., Sun, M., Wang, Q., Coppola, D., Mansour, M., Xu, L.M., Costanzo, C., Cheng, J.Q. and Wang, L.H. (2008) Twist is transcriptionally induced by activation of STAT3 and mediates STAT3 oncogenic function. The Journal of Biological Chemistry, 283, 1466514673. doi:10.1074/jbc.M707429200

[7] Valdés-Mora, F., Gómez del Pulgar, T., Bandrés, E., Cejas, P., Ramírez, A., Pérez-Palacios, R., Gallego-Ortega, D., García-Cabezas, M.A., Casado, E., Larrauri, J., Nistal, M., González-Barón, M., García-Foncillas, J. and Lacal, J.C. (2009) Twist 1 overexpression is associated with nodal invasion and male sex in primary colorectal cancer. Annals of Surgical Oncology, 16, 78-87. doi:10.1245/s10434-008-0166-X

[8] Maruvada, P. and Srivastava, S. (2004) Biomarkers for cancer diagnosis: Implications for nutritional research. The Journal of Nutrition, 134, 1640S-1645S.

[9] Cheng, G.Z., Zhang, W. and Wang, L.H. (2008) Regulation of cancer cell survival, migration, and invasion by Twist: AKT2 comes to interplay. Cancer Research, 68, 957-960. doi:10.1158/0008-5472.CAN-07-5067

[10] Shiota, M., Izumi, H., Onitsuka, T., Miyamoto, N., Kashiwagi, E., Kidani, A., Yokomizo, A., Naito, S. and Kohno, K. (2008) Twist promotes tumor cell growth through YB-1 expression. Cancer Research, 68, 98-105. doi:10.1158/0008-5472.CAN-07-2981

[11] Mehrotra, J., Vali, M., McVeigh, M., Kominsky, S.L., Fackler, M.J., Lahti-Domenici, J., Polyak, K., Sacchi, N., Garrett-Mayer, E., Argani, P. and Sukumar, S. (2004) Very high frequency of hypermethylated genes in breast cancer metastasis to the bone, brain, and lung. Clinical Cancer Research, 10, 3104-3109. doi:10.1158/1078-0432.CCR-03-0118

[12] Ciccolini, J., Peillard, L., Aubert, C., Formento, P., Milano, G. and Catalin, J. (2000) Monitoring of the intracellular activation of 5-fluorouracil to deoxyribonucleo- tides in HT29 human colon cell line: Application to modulation of metabolism and cytotoxicity study. Fundamental and Clinical Pharmacology, 14, 147-154. doi:10.1111/j.1472-8206.2000.tb00403.x

[13] García-Gasca, T., Salazar-Olivo, L.A., Mendiola-Olaya, E. and Blanco-Labra, A. (2002) The effects of a protease inhibitor fraction from tepary bean (Phaseolus acutifolius) on in vitro cell proliferation and cell adhesion of transformed cells. Toxicology in Vitro, 16, 229-233. doi:10.1016/S0887-2333(02)00006-1

[14] Ganguly, S., Ashley, L.A., Pendleton, C.M., Grey, R.D., Howard, G.C., Castle, L.D., Peyton, D.K., Fultz, M.E. and DeMoss, D.L. (2008) Characterization of osteoblastic properties of 7F2 and UMR-106 cultures after acclimation to reduced levels of fetal bovine serum. Canadian Journal of Physiology and Pharmacology, 86, 403-415. doi:10.1139/Y08-055

[15] Lui, K.O., Waldmann, H. and Fairchild, P.J. (2009) Embryonic stem cells: Overcoming the immunological barriers to cell replacement therapy. Current Stem Cell Research and Therapy, 4, 70-80. doi:10.2174/157488809787169093

[16] Zanghi, J.A., Fussenegger, M. and Bailey, J.E. (1999) Serum protects protein-free competent Chinese hamster ovary cells against apoptosis induced by nutrient deprivation in batch culture. Biotechnology and Bioengineering, 64, 108-119. doi:10.1002/(SICI)1097-0290(19990705)64:1<108::AID -BIT12>3.0.CO;2-B

[17] De Castro, M., Orive, G., Gascón, A.R., Hernández, R.M. and Pedraz, J.L. (2006) Evaluation of human serum albumin as a substitute of fetal bovine serum for cell culture. International Journal of Pharmaceutics, 310, 8-14. doi:10.1016/j.ijpharm.2005.10.028

[18] Medina, M.A. (2001) Glutamine and Cancer. The Journal of Nutrition, 131, 2539S-2542S.

[19] Pan, Y., Bender, P., Akers, R. and Webb, K. (1998) One or more serum factors promote peptide utilization in cultured animal cells. The Journal of Nutrition, 128, 744750 .

[20] Kamath, S., Conrad, N., Olson, R., Bess, M., Mid, O. and Ghosh, L. (1988) Amino acid-restricted diets in the treatment of mammary adenocarcinoma in mice. The Journal of Nutrition, 118, 1137-1142.

[21] Theuer, R.C. (1971) Effect of essential amino acid restriction on the growth of female C57BL mice and their implant BW1023 adenocarcinomas. The Journal of $\mathrm{Nu}$ trition, 101, 223-232.

[22] Worthington, B., Yrotuck, J. and Ahmed, S. (1978) Effects of essential amino acid deficiencies on syngeneic tumor inmmunity and carcinogenesis in mice. The Journal of Nutrition, 108, 1402-1411.

[23] Yen, C., Mar, M., Craciunescu, C., Edwards, L. and Zeisel, S. (2002) Deficiency in methionine, tryptophan, isoleucine, or choline induces apoptosis in cultured cells. The Journal of Nutrition, 132, 1840-1847.

[24] Choudry, H.A., Pan, M., Karinch, A.M. and Souba, W.W. (2006) Branched-chain amino acid-enriched nutritional support in surgical and cancer patients. The Journal of Nutrition, 136, 314S-318S.

[25] Sawada, K., Noda, K., Nakajima, H., Shimbara, N., Furuichi, Y. and Sugimoto, M. (2005) Differential cytotox- 
icity of anticancer agents in pre- and post-immortal lymphoblastoid cell lines. Biological and Pharmaceutical Bulletin, 28, 1202-1207. doi:10.1248/bpb.28.1202

[26] Misaki, T., Iwata, M., Iida, Y., Kasagi, K. and Konishi, J. (2002) Chemo-radionuclide therapy for thyroid cancer: Initial experimental study with cultured cells. Annals of Nuclear Medicine, 16, 403-408.

doi:10.1007/BF02990078

[27] Brunetti, I., Falcone, A., Calabresi, P., Goulette, F. and Darnowski, J. (1990) 5-Fluorouracil enhances azidothymidine cytotoxicity: in vitro, in vivo, and biochemical studies. Cancer Research, 50, 4026-4031.

[28] Tillman, D.M., Petak, I. and Houghton, J.A. (1999) A fas-dependent component in 5-fluorouracil/leucovorin-induced cytotoxicity in colon carcinoma cells. Clinical Cancer Research, 5, 425-430.

[29] Hao, N., Whitelaw, M.L., Shearwin, K.E., Dodd, I.B. and Chapman-Smith, A. (2011) Identification of residues in the N-terminal PAS domains important for dimerization of Arnt and AhR. Nucleic Acids Research, 39, 36953709. doi:10.1093/nar/gkq1336 